\title{
Silencing of FRAT1 by siRNA inhibits the proliferation of SGC7901 human gastric adenocarcinoma cells
}

\author{
QINGGONG YU ${ }^{1}, \mathrm{LU} \mathrm{SHANG}^{1}, \mathrm{HONGBO} \mathrm{YU}^{2}, \mathrm{ZIRONG} \mathrm{YANG}^{1}$ and DEKUI XU ${ }^{1}$ \\ Departments of ${ }^{1}$ Gastroenterology and ${ }^{2}$ Infectious Diseases, Affiliated Zhongshan \\ Hospital of Dalian University, Dalian, Liaoning 116001, P.R. China
}

Received April 5, 2015; Accepted January 5, 2016

DOI: $10.3892 /$ br.2016.571

\begin{abstract}
Frequently rearranged in advanced $\mathrm{T}$ cell lymphomas-1 (FRAT1) positively regulates the Wnt/ $\beta$-catenin signaling pathway by inhibiting glycogen synthase kinase- 3 mediated phosphorylation of $\beta$-catenin. FRAT1 is a proto-oncogene, implicated in tumorigenesis. The present study aimed to investigate the effects of FRAT1 silencing on the proliferation and apoptosis of SGC7901 cells. FRAT1 in SGC7901 cells was silenced by RNA interference. Reverse transcription-quantitative polymerase chain reaction was used for the analysis of FRAT1 mRNA and western blotting was used to evaluate FRAT1 and $\beta$-catenin protein levels. Cell proliferation was analyzed by the MTT assay. Cell cycle distribution and apoptosis were analyzed by flow cytometry. The expression of FRAT1 mRNA, FRAT1 and $\beta$-catenin protein in FRAT1-silenced SGC7901 cells were reduced significantly compared to untreated cells. The proliferation of FRAT1 silenced SGC7901 cells decreased significantly The FRAT1 silenced SGC7901 cells were arrested at G0/G1 stage to a greater degree, and apoptosis was increased. In summary, silencing of FRAT1 inhibits SGC7901 cell proliferation and induces apoptosis, possible through a reduction in $\beta$-catenin expression. FRAT1 may serve as a prognostic biomarker and therapeutic target for gastric cancer.
\end{abstract}

\section{Introduction}

Gastric cancer is one of the most common human cancers, with $\sim 988,000$ cases/year worldwide. It remains difficult to treat and $\sim 736,000$ patients succumb to the disease each year (1).

Correspondence to: Dr Dekui Xu, Department of Gastroenterology, Affiliated Zhongshan Hospital of Dalian University, 6 Jiefang Street, Dalian, Liaoning 116001, P.R. China

E-mail: xudekui2012@yahoo.com

Abbreviations: FRAT1, frequently rearranged in advanced $\mathrm{T}$ cell lymphomas-1; RT-qPCR, reverse transcription-quantitative polymerase chain reaction; MTT, methyl thiazolyl tetrazolium

Key words: frequently rearranged in advanced T cell lymphomas-1, RNA interference, proliferation, apoptosis, SGC7901 cells
In China, gastric cancer is the leading cause of cancer-related mortality and accounts for $\sim 23 \%$ of all malignant deaths (2). It has been previously demonstrated that gastric cancer is caused by complex interactions between genetic and environmental factors. The dysregulation of potential oncogenic signaling pathways can lead to increased cell proliferation, evasion of apoptosis and enhanced invasiveness (3). Furthermore, the dysregulation of the nuclear factor $\kappa \mathrm{B}, \mathrm{Wnt} / \beta$-catenin and proliferation/stem cell signaling pathways are identified in $70 \%$ patients with gastric cancer (4). Frequently rearranged in advanced T cell lymphomas-1 (FRAT1) is a member of the FRAT family, and is a positive regulator of $\beta$-catenin in the Wnt pathway (5). The Wnt/ $\beta$-catenin pathway is closely associated with the pathogenesis and development of many solid tumors. The overexpression of FRAT1 in ovarian serous adenocarcinomas was significantly associated with cytoplasmic and nuclear accumulation of $\beta$-catenin 6). FRAT1 inhibited GSK-3-mediated phosphorylation of $\beta$-catenin and affected the formation of the destruction complex for $\beta$-catenin, leading to subsequent aberrant nuclear accumulation of $\beta$-catenin, which elevated the transcription activity of $\beta$-catenin. The downstream transcription targets of $\beta$-catenin pathway, such as c-myc, were activated to enhance the cellular growth $(7,8)$. Additionally, a previous study has demonstrated that FRAT1 is overexpressed in gastric cancer (9). The present study aimed to investigate the effects of FRAT1 silencing on the proliferation, apoptosis and the cell cycle of the human gastric cancer cell line, SGC7901.

\section{Materials and methods}

Cell culture. Human gastric adenocarcinoma SGC7901 cells were obtained from the Institute of Basic Medical Sciences (Chinese Academy of Medical Science, Beijing, China). Cells were maintained in RPMI-1640 (GE Healthcare Life Sciences, Logan, UT, USA) supplemented with $10 \%$ fetal bovine serum, $100 \mathrm{U} / \mathrm{ml}$ penicillin and $100 \mathrm{mg} / \mathrm{ml}$ streptomycin (all from GE Healthcare Life Sciences), at $37^{\circ} \mathrm{C}$ in a humidified atmosphere containing $5 \% \mathrm{CO}_{2}$. The medium was replaced every two days and cells were passaged twice weekly.

Transfection. The oligonucleotide sequence 5'-GCAGTT ACGTGCAAAGCTT-3' (Takara Biotechnology Co., Ltd., Dalian, China), specific to FRATl mRNA was used for the synthesis of small interfering RNA (siRNA), which was cloned 
into pSINsi-hu6 vector (Takara Biotechnology). SGC7901 cells were transfected with the siFRAT1 vector using Lipofectamine ${ }^{\circledR} 2000$ (Invitrogen Life Technologies, Carlsbad, CA, USA), performed according to the manufacturer's instructions. The transfected SCG7901 cells were screened using $800 \mu \mathrm{g} / \mathrm{ml}$ G418 (Gibco; Thermo Fisher Scientific, Inc., Waltham, MA, USA) and were defined as group A (10). The non-targeting oligonucleotide sequence 5'-TCTTAATCGCGTATAAGGC-3' (Takara Biotechnology) was transfected as a control group B. The untreated SGC7901 cells were defined as group C.

FRAT1 mRNA expression analysis. FRAT1 mRNA expression was assessed by reverse transcription-quantitative polymerase chain reaction (RT-qPCR). TRIzol reagent RNA kit (Invitrogen; Thermo Fisher Scientific) was used to extract total RNA, following the protocol provided by the manufacturer. Takara RNA PCR kit (Takara Biotechnology) was used to perform the reverse transcriptase polymerase chain reaction. The following primers were used. FRAT1: Forward, 5'-GGC AGAACCTGGCTACTCTG-3' and reverse 5'-CACGAGCTT GATTGCAAGTTCAGG-3'; GAPDH: Forward 5'-CCACGC CCTGTCTAAAGTGT-3' and reverse 5'-GGGGTCATTGAT GGCAACAATA-3' (Takara Biotechnology). The complementary DNA mixed with forward and reverse primers was reacted in Exicycler ${ }^{\mathrm{TM}} 96$ (Bioneer Co., Daejeon, Korea). An initial denaturation/activation step at $95^{\circ} \mathrm{C}$ for $10 \mathrm{~min}$ was followed by 35 cycles at $95^{\circ} \mathrm{C}$ for $10 \mathrm{sec}, 60^{\circ} \mathrm{C}$ for $20 \mathrm{sec}$ and $72^{\circ} \mathrm{C}$ for $30 \mathrm{sec}$, finally held at $4^{\circ} \mathrm{C}$ for $5 \mathrm{~min}$. The FRAT1 mRNA relative expression ratio was calculated using the $2^{-\Delta \Delta c q}$ method, and the result of group $\mathrm{C}$ was considered the unit value 1 .

FRAT1 and $\beta$-catenin protein expression analysis. Western blot analysis was used to measure the protein expression levels of FRAT1 and $\beta$-catenin. Anti-FRAT1 (cat. no. ab108405) and anti- $\beta$-actin (cat. no. ab95437) antibodies were purchased from Abcam, Cambridge, UK. The anti- $\beta$-catenin antibody was purchased from Santa Cruz Biotechnology, Inc. (Dallas, TX, USA). The optical density of bands was measured by Image-Pro Plus software, version 6.0 (Media Cybernetics, Inc., Rockville, MD, USA). Protein expression was reported as relative level with respect to the $\beta$-actin in the same sample, and the value of group $\mathrm{C}$ was considered the unit value 1 .

Cells proliferation assay. The SGC7901 cells were seeded into a 96-well cell culture cluster plate at a concentration of $1 \times 10^{4}$ cells/well in a volume of $100 \mu \mathrm{l}$ culture medium and cultured for $24 \mathrm{~h}$. A $200 \mu \mathrm{l}$ RPMI-1640 culture medium supplemented with $10 \%$ fetal bovine serum was then added into every well and the cells were harvested at 24,48 and $72 \mathrm{~h}$. The harvested cells were incubated in $200 \mu \mathrm{l}$ RPMI-1640 culture medium supplemented with $0.5 \%$ 3-(4,5-dimethylthiazol-2-yl)-2,5-diphenyltetrazolium bromide (KeyGen Biotech. Co., Ltd., Nanjing, China) for $4 \mathrm{~h}$ and then $150 \mu \mathrm{l}$ of dimethyl sulphoxide was added to dissolve the formazan crystals for 10 min immediately prior to the assay. Absorbency was measured at a wavelength of $490 \mathrm{~nm}$ using a microplate reader (Bio-Rad, Berkeley, CA, USA). The assay was repeated $\geq 3$ times for cell proliferation analysis.

Cells cycle analysis. The SGC7901 cells were cultured in $25 \mathrm{ml}$ culture bottle to a confluence of $80 \%$ and then treated

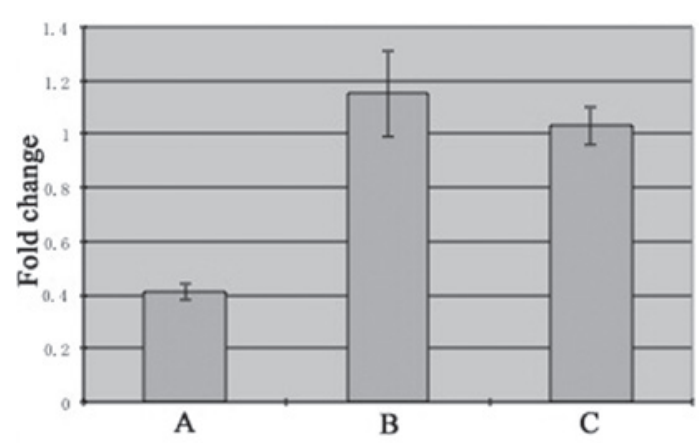

Figure 1. Relative expression of frequently rearranged in advanced $\mathrm{T}$ cell lymphomas-1 (FRAT1) mRNA in SGC7901 cells. FRAT1 of SGC7901 cells was silenced by RNA interference. (A) FRAT1 silenced SGC7901 cells. (B) Control group of SGC7901 cells. (C) Untreated SGC7901 cells.

with trypsogen (GE Healthcare Life Sciences) to harvest the cells. The cells were then fixed in $75 \%$ ethanol overnight at $4^{\circ} \mathrm{C}$ and incubated with $50 \mathrm{mg} / \mathrm{L}$ RNase A (GE Healthcare Life Sciences) at $37^{\circ} \mathrm{C}$ for $30 \mathrm{~min}$. Flow cytometry was performed after the cells were stained with a $50 \mathrm{mg} / \mathrm{L}$ propidium iodide solution (BD FACScan; BD Biosciences, San Diego, CA, USA) for $20 \mathrm{~min}$ in the dark.

Apoptosis assay. The SGC7901 cells were seeded into a 96-well cell culture cluster plate and incubated for $48 \mathrm{~h}$. The cells were then harvested by trypsinization and washed twice with $4^{\circ} \mathrm{C}$ phosphate buffered saline. Cells were then suspended in $1 \mathrm{ml}$ binding buffer $(0.01 \mathrm{M}$ HEPES/NaOH, $0.14 \mathrm{M} \mathrm{NaCl}$, $\left.2.5 \mathrm{mM} \mathrm{CaCl}_{2}, \mathrm{pH} 7.4\right)$ at a concentration of $1-5 \times 10^{5}$ cells $/ \mathrm{ml}$. Annexin V-fluorescein isothiocyanate $(10 \mu \mathrm{l})$ (BD Biosciences) and propidium iodide (5 $\mu \mathrm{l})$ (BD Biosciences) were added to the cells, followed by incubation with gentle mixing for $15 \mathrm{~min}$ at room temperature in the dark. The Annexin V stained cells were analyzed using a BD Model FACScan (BD Biosciences).

Statistical analysis. Data are presented as the mean \pm standard deviation. SPSS 13.0 (SPSS, Inc., Chicago, IL, USA) was used for data analysis. $\mathrm{P}<0.05$ was considered to indicate a statistically significant difference.

\section{Results}

FRAT1 expression. The relative expression of FRAT1 mRNA in SGC7901 cells treated with siFRAT1 (group A; $0.41 \pm 0.03$ ) was decreased significantly compared with control groups B $(1.15 \pm 0.16, \mathrm{P}<0.05)$ and $\mathrm{C}(1.03 \pm 0.07, \mathrm{P}<0.05)$ (Fig. 1). The expression of FRAT1 protein in group A $(0.35 \pm 0.07)$ was decreased significantly compared with control groups B $(1.10 \pm 0.08, \mathrm{P}<0.05)$ and $\mathrm{C}(1.01 \pm 0.04, \mathrm{P}<0.05)$ (Fig. 2$)$. These results indicate that the silencing of FRAT1 by siRNA targeting FRAT1 in SGC7901 cells was successful.

$\beta$-catenin expression. The expression of $\beta$-catenin protein in SGC7901 cells treated with siFRAT1 (group A; 0.38 \pm 0.08 ) was decreased significantly compared with the control group B $(1.17 \pm 0.25, \mathrm{P}<0.05)$ and untreated group C $(1.09 \pm 0.13$, $\mathrm{P}<0.05$ ) (Fig. 3). 
Table I. Proliferation of SGC7901 cells, $n=3$.

Time, h

\begin{tabular}{lcccc}
\cline { 2 - 5 } Group & 0 & 24 & 48 & 72 \\
\hline A & $0.26 \pm 0.02$ & $0.33 \pm 0.01$ & $0.36 \pm 0.01^{\mathrm{a}}$ & $0.39 \pm 0.01^{\mathrm{a}}$ \\
B & $0.27 \pm 0.03$ & $0.35 \pm 0.01$ & $0.54 \pm 0.01$ & $0.69 \pm 0.00$ \\
C & $0.26 \pm 0.01$ & $0.35 \pm 0.02$ & $0.57 \pm 0.03$ & $0.68 \pm 0.02$
\end{tabular}

${ }^{\mathrm{a}} \mathrm{P}<0.05$, group A vs. groups B and C. Group A, frequently rearranged in advanced T cell lymphomas-1 silenced SGC7901 cells. B, control group of SGC7901 cells. C, untreated SGC7901 cells.
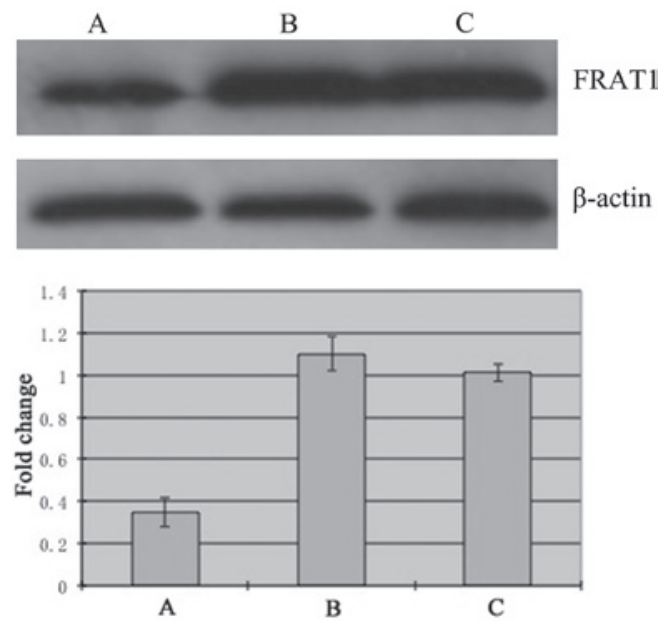

Figure 2. Western blotting of frequently rearranged in advanced $\mathrm{T}$ cell lymphomas-1 (FRAT1) protein in SGC7901 cells. FRAT1 of SGC7901 cells was silenced by RNA interference. (A) FRAT1 silenced SGC7901 cells (B) Control group of SGC7901 cells. (C) Untreated SGC7901 cells.
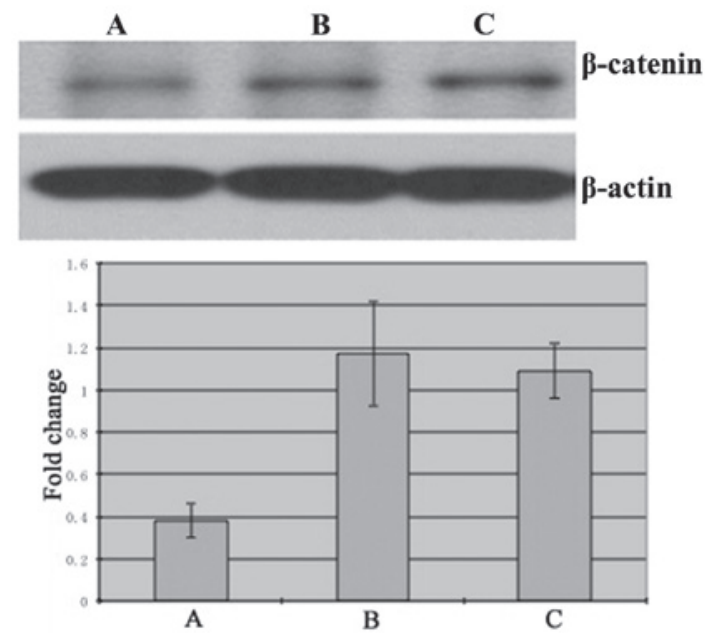

Figure 3. Western blotting of $\beta$-catenin protein in SGC7901 cells. Frequently rearranged in advanced T cell lymphomas-1 (FRAT1) of SGC7901 cells was silenced by RNA interference. (A) FRAT1 silenced SGC7901 cells. (B) Control group of SGC7901 cells. (C) Untreated SGC7901 cells.

Cells proliferation. The cells proliferation in siFRAT1-treated group A was decreased significantly compared with control groups $\mathrm{B}$ and $\mathrm{C}$ at $48 \mathrm{~h}(\mathrm{P}<0.05)$ and $72 \mathrm{~h}(\mathrm{P}<0.05)$ (Table I).
Table II. Cell cycle distribution of SGC7901 cells, $n=3$.

\begin{tabular}{lccc}
\hline & \multicolumn{3}{c}{ Cell cycle phase } \\
\cline { 2 - 4 } Group & G0/G1 & $\mathrm{S}$ & $\mathrm{G} 2 / \mathrm{M}$ \\
\hline A & $73.02 \pm 0.52^{\mathrm{a}}$ & $18.75 \pm 0.39^{\mathrm{a}}$ & $2.70 \pm 0.17^{\mathrm{a}}$ \\
B & $61.77 \pm 0.08$ & $26.45 \pm 0.12$ & $6.44 \pm 0.11$ \\
C & $63.93 \pm 0.64$ & $25.99 \pm 0.62$ & $6.45 \pm 0.09$ \\
\hline
\end{tabular}

${ }^{\mathrm{a}} \mathrm{P}<0.05$, group A vs. groups B and C. Group A, frequently rearranged in advanced T cell lymphomas-1 silenced SGC7901 cells. B, control group of SGC7901 cells. C, untreated SGC7901 cells.
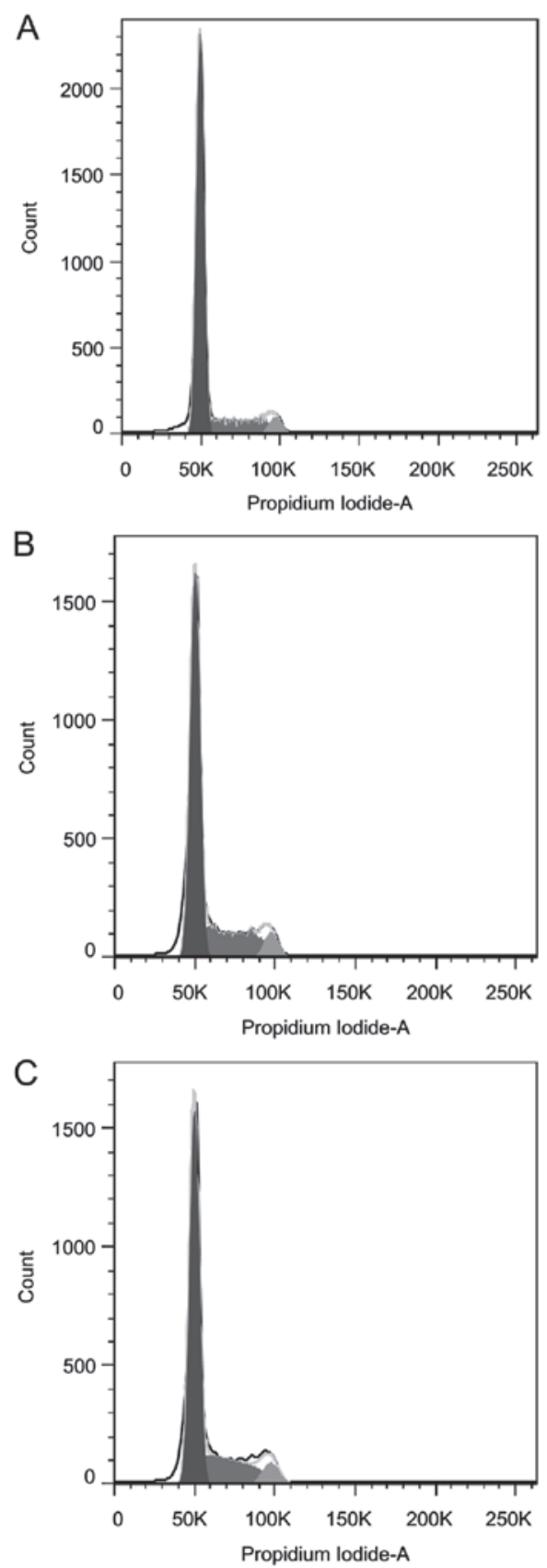

Figure 4. Cell cycle analysis of SGC7901 cells. Frequently rearranged in advanced T cell lymphomas-1 (FRAT1) of SGC7901 cells was silenced by RNA interference. (A) FRAT1 silenced SGC7901 cells. (B) Control group of SGC7901 cells. (C) Untreated SGC7901 cells. 
These results demonstrate that the silencing of FRAT1 inhibited the proliferation of SGC7901 cells.

Cells cycle. The cell cycle distribution in siFRAT1-treated group A was significantly different to that of the control groups $B$ and $C$. The G0/G1 stage cells in group $A$ was increased significantly compared with groups $\mathrm{B}$ and $\mathrm{C}(\mathrm{P}<0.05)$. The $\mathrm{S}$ and $\mathrm{G} 2 / \mathrm{M}$ stage cells in group $\mathrm{A}$ was decreased significantly compare with groups B and $\mathrm{C}(\mathrm{P}<0.05)$ (Table II and Fig. 4). These results demonstrate that the silencing of FRAT1 in SGC7901 cells led to increased arrest at the G0/G1 stage.

Cells apoptosis. The fraction of apoptosis in siFRAT1-treated group A (3.87 \pm 0.08$)$ was increased significantly compared with control groups $\mathrm{B}(1.62 \pm 0.02, \mathrm{P}<0.05)$ and $\mathrm{C}(1.22 \pm 0.02$, $\mathrm{P}<0.05)$. These results demonstrate that the silencing of FRAT1 in SGC7901 cells led to an increase in apoptosis.

\section{Discussion}

The FRAT1 gene is located on human chromosome 10q24.1 and encodes a protein comprising 279 amino acids that is overexpressed in gastric cancer (9). FRAT1 can inhibit glycogen synthase kinase- 3 mediated phosphorylation of $\beta$-catenin and act as a positive regulator of the $\mathrm{Wnt} / \beta$-catenin pathway $(11,12)$. The Wnt $/ \beta$-catenin signaling cascade modulates the expression of genes that govern cell proliferation, cell survival, migration, neural development and angiogenesis during morphogenesis (13-16). It has been previously demonstrated that FRAT1 plays a important role in tumor progression $(17,18)$. FRAT1 inhibits the phosphorylation of $\beta$-catenin, causing it to accumulate in the nucleus. $\beta$-catenin then binds with $\mathrm{T}$ cell transcriptional factor/lymphoid enhancer factor to form a complex, which can drive c-myc, Cox-2 and cyclin D1 to alter the cell cycle or express abnormal protein leading to the tumorigenesis (19). Furthermore, overexpression of FRAT1 in transgenic mice leads to lymphoma progression (20) and knockdown of FRAT1 by RNA interference inhibits glioblastoma cell growth, migration and invasion (21). Additionally, the overexpression of FRAT1 is associated with a malignant phenotype and poor prognosis in human gliomas (22).

The present study demonstrates that FRAT1 mRNA and protein expression in SGC7901 cells was inhibited by RNA interference. The expression of FRAT1 mRNA and FRAT1 protein were reduced significantly in comparison to untreated cells. The results also demonstrate that the expression of $\beta$-catenin protein was significantly decreased. Furthermore, the proliferation of FRAT1 silenced SGC7901 cells decreased significantly and the cell cycle distribution was significantly different from the untreated cells, with more cells arrested at G0/G1 stage. Apoptosis of FRAT1 silenced SGC7901 cells was increased significantly.

In conclusion, the results of the present study indicate that FRAT1 is important for the proliferation of SGC7901 cells and silencing of FRAT1 by siRNA can inhibit the proliferation of the SGC7901 cells. A reduction in the expression of $\beta$-catenin may be a potential mechanism for the effects of FRAT1 silencing on cell proliferation, apoptosis and cell cycle distribution. FRAT1 may be a potential prognostic biomarker and therapeutic target for gastric cancer.

\section{Acknowledgements}

The study was supported by a fund from the Science and Technology of Dalian Public Health Bureau, Liaoning, China (grant no. 2014.142).

\section{References}

1. Kamangar F, Dores GM and Anderson WF: Patterns of cancer incidence, mortality, and prevalence across five continents: defining priorities to reduce cancer disparities in different geographic regions of the world. J Clin Oncol 24: 2137-2150, 2006.

2. Zou XN, Duan JJ, Huangfu XM, Chen WQ and Zhao P: Analysis of stomach cancer mortality in the national retrospective sampling survey of death causes in China, 2004-2005. Zhonghua Yu Fang Yi Xue Za Zhi 44: 390-397, 2010 (In Chinese).

3. Wu WK, Cho CH, Lee CW, Fan D, Wu K, Yu J and Sung JJ: Dysregulation of cellular signaling in gastric cancer. Cancer Lett 295: 144-153, 2010.

4. Ooi CH, Ivanova T, Wu J, Lee M, Tan IB, Tao J, Ward L, Koo JH, Gopalakrishnan V, Zhu Y, et al: Oncogenic pathway combinations predict clinical prognosis in gastric cancer. PLoS Genet 5: e1000676, 2009.

5. Jonkers J, Korswagen HC, Acton D, Breuer M and Berns A: Activation of a novel proto-oncogene, Frat1, contributes to progression of mouse T-cell lymphomas. EMBO J 16: 441-450, 1997.

6. Wang Y, Hewitt SM, Liu S, Zhou X, Zhu H, Zhou C, et al: Tissue microarray analysis of human FRAT1 expression and its correlation with the subcellular localisation of beta-catenin in ovarian tumours. Br J Cancer 94: 686-691, 2006.

7. Wang Y, Liu S, Zhu H, Zhang W, Zhang G, Zhou X, Zhou C, Quan L, Bai J, Xue L, et al: FRAT1 overexpression leads to aberrant activation of beta-catenin/TCF pathway in esophageal squamous cell carcinoma. Int J Cancer 123: 561-568, 2008.

8. Guo G, Mao X, Wang P, Liu B, Zhang X, Jiang X, Zhong C, Huo J, Jin J and Zhuo Y: The expression profile of FRAT1 in human gliomas. Brain Res 1320: 152-158, 2010.

9. Saitoh T and Katoh M: FRAT1 and FRAT2, clustered in human chromosome 10q24.1 region, are up-regulated in gastric cancer. Int J Oncol 19: 311-315, 2001 .

10. Yu QG, Gu W, Wang SY, Zhang XX, Yang ZR and Li WS: Establishment of FRAT1 gene silence HT29 cells model by RNA interference. China Mod Med 21: 12-15, 2014.

11. Jonkers J, van Amerongen R, van der Valk M, Robanus-Maandag E, Molenaar M, Destrée O and Berns A: In vivo analysis of Frat1 deficiency suggests compensatory activity of Frat3. Mech Dev 88: 183-194, 1999.

12. Yost C, Farr GH III, Pierce SB, Ferkey DM, Chen MM and Kimelman D: GBP, an inhibitor of GSK-3, is implicated in Xenopus development and oncogenesis. Cell 93: 1031-1041, 1998.

13. Logan CY and Nusse R: The Wnt signaling pathway in development and disease. Annu Rev Cell Dev Biol 20: 781-810, 2004.

14. Liebner S and Plate KH. Differentiation of the brain vasculature: the answer came blowing by the Wnt. J Angiogenes Res 2: 1, 2010.

15. Ille F and Sommer L: Wnt signaling: multiple functions in neural development. Cell Mol Life Sci 62: 1100-1108, 2005.

16. Reis M and Liebner S: Wnt signaling in the vasculature. Exp Cell Res 319: 1317-1323, 2013.

17. Saitoh T, Mine T and Katoh M: Molecular cloning and expression of proto-oncogene FRAT1 in human cancer. Int J Oncol 20: 785-789, 2002.

18. Zhang Y, Han Y, Zheng R, Yu JH, Miao Y, Wang L and Wang EH: Expression of Frat 1 correlates with expression of $\beta$-catenin and is associated with a poor clinical outcome in human SCC and AC. Tumour Biol 33: 1437-1444, 2012.

19. Chiurillo MA: Role of the Wnt/ $\beta$-catenin pathway in gastric cancer: An in-depth literature review. World J Exp Med 5: 84-102, 2015.

20. Jonkers J, Weening JJ, van der Valk M, Bobeldijk R and Berns A: Overexpression of Frat1 in transgenic mice leads to glomerulosclerosis and nephrotic syndrome, and provides direct evidence for the involvement of Frat1 in lymphoma progression. Oncogene 18: 5982-5990, 1999.

21. Guo G, Kuai D, Cai S, Xue N, Liu Y, Hao J, Fan Y, Jin J, Mao X, Liu B, et al: Knockdown of FRAT1 expression by RNA interference inhibits human glioblastoma cell growth, migration and invasion. PLoS One 8: e61206, 2013.

22. Guo G, Zhong CL, Liu Y, Mao XG, Zhang Z, Jin J, et al: Overexpression of FRAT1 is associated with malignant phenotype and poor prognosis in human gliomas. Dis Markers 2015: 289750, 2015. 